\title{
Environmental Resource - Economized Processes of Recycling Mineral Raw Materials of Complex Composition
}

\author{
Vinnikov V.A., ${ }^{1}$ Silberschmidt M.G., ${ }^{1}$ Bocharov V.A., ${ }^{1}$ Ignatkina V.A., ${ }^{2}$ Gzogyan T.N. ${ }^{3}$ \\ 1 - Moscow State Mining University. Address: Leninsky ave.,6,Moscow, Russia, 117953; \\ 2 - Moscow Institute of Steel and Alloys. Address: Leninsky ave.,4,Moscow, Russia,117953; \\ 3 - VIOGEM. Address: B. Khmelnytsky ave. 86, Belgorod, Russia, 308007
}

\begin{abstract}
The results of the studies on the justification of technological processes providing recycling of the warehoused ferruginous quartzites of complex composition and waste non-ferrous metals allowing to receive additional commodity products are given. The example of amphibole and biotite varieties of ferruginous quartzites of CMA and tailings of copper-zinc sulphide Ural ores determines the reasons of ineffective use of traditional technology solutions for recycling. The reasons of environmental hazards concerning varieties of technogenic mineral substances to the environment are identified. The presence in ferruginous quartzites complex composition of various silicates, carbonates and iron sulphides change their technological properties. So to get the iron concentrate from them suggests a new combination of technological operations performed in specially selected operating conditions. The specifics of the presence of mineral components in solid mineral wastes of nonferrous metal ores indicates the possibility of obtaining additional marketable products. With the use of laboratory multiscale modelling and physical methods of analysis regularities of variation of fractionation, separation and mineral concentration operations efficiency by varying its composition and the various influencing factors are identified. To improve the efficiency of the individual technological operations it is recommended to use different techniques, using physical and physicochemical effects on the polymineral systems. The flow diagrams for the considered varieties of technogenic processing of mineral substances, allowing them to obtain standared quality products (metal-containing concentrates), and the results of their testing are submitted. The suggested technological solutions can reduce the amount of environmentally hazardous mineral substance, hosted in technogenic formations.
\end{abstract}

Keywords - resource conservation, ferruginous quartzites, non-metal ores, mineral resources, technogenic formations

\section{INTRODUCTION}

Intensive development of mineral deposits is often accompanied by deterioration of the geological conditions of their mining, leads to an increase in the amount of recoverable from the subsoil complex composition mineral raw. Because of the significant difference of technological properties from conditional varieties of minerals, its processing in the production capacity of existing enterprises is not carried out [1].

Thus, on the average, only $10-20 \%$ of the recovered from the depths of the mineral matter (the rock) is used to obtain the final commercial product. The rest of it, although it contains useful components placed in man-made formations (tailings, sludge warehouses, etc.) that adds up to Russia about 2.5 billion tons per year. This situation has a negative impact on the economic performance of enterprises.

Accumulated in the central regions of Russia manmade mineral waste of mining and mineral processing occupied the total area of about 0.7 million hectares, situated mainly in industrialized regions with high density of population.

Disintegrated state of located on the surface manmade mineral substance provides free access to a natural fluids (liquids and gases) causes an intensive flow of hypergenic processes (oxidation, hydration, interaction of the components), and the presence of heavy metals and toxic elements in solid-phase contributes to migration of hazardous components including the hydrosphere and, as a consequence, the deterioration of the environmental situation in the mining regions [2].

Along with this, the mineral substance of technogenic formations contains useful components, shortage of which have various industries, so it can be considered as an additional resource base.

\section{MATERIALS AND METHODS}

Radical solution to the resource and environmental problems associated with the formation and storage of unused types of mineral matter of natural and anthropogenic origin, is to reduce its volume, through their recycling using specially developed technology.

Ferruginous quartzite of complex composition of Lebedinsky ore deposit and tailings of copper-zinc sulphide Ural ores (for example, waste ore at JSC "Svyatogor") is the subject of the research.

The study of the composition, structure and structural condition features of mineral matter of ferruginous quartzite of complex composition and tailings of copper-zinc sulphide Ural ores was carried out with the use of complex methodological approach that uses multiple physical and physico-chemical 
analysis of mineral matter which data cannot only confirm, but also complement each other.

The purpose of the study is to develop technological methods of processing of man-made mineral matter which gained a conditioning commercial products that improve the environmental situation in the regions

\section{Ferruginous quartzite of complex composition}

Studies have shown that ferruginous quartzites of complex composition of Lebedinsky deposit are typical very finely disseminated ores and significant differences in material composition, variety of textural and structural features of non-uniform impregnation of metallic and non-metallic minerals with similar physical and chemical properties/

By ferruginous quartzite complex of composition are kummangtonit-magnetite and biotite-magnetite ferruginous quartzite species; the features of their structure can be judged on the basis of the data presented in Table 1.

TABLE 1

THE DIFFERENCES OF THE MINERAL COMPOSITION OF THE MINERAL PROCESSING SAMPLES OF FERRUGINOUS QUARTZITE OF LEBEDINSKY DEPOSIT

\begin{tabular}{|l|l|l|l|}
\hline Minerals & $\begin{array}{l}\text { Magnetite } \\
\text { quartzites }\end{array}$ & $\begin{array}{l}\text { Cummingtonite- } \\
\text { magnetite } \\
\text { quartzites }\end{array}$ & $\begin{array}{l}\text { Biotite- } \\
\text { magnetite } \\
\text { quartzites }\end{array}$ \\
\hline Quartz & $29,5-34,5$ & $32,2-37$ & $12,5-17,5$ \\
\hline Magnetite & $34-39$ & $26,6-31,5$ & $30-35$ \\
\hline Hematite & $1,73-2,0$ & $0,15-0,2$ & - \\
\hline All carbonates & $2,6-3,5$ & $8,1-13$ & $2,5-5,0$ \\
\hline All amphiboles & $13,5-17,0$ & $18,5-22,5$ & $30-35$ \\
\hline Aegirine & $0,5-2$ & - & - \\
\hline $\begin{array}{l}\text { Biotite + green } \\
\text { mica }\end{array}$ & $2,5-4,5$ & $7,6-11,5$ & $9-13,5$ \\
\hline $\begin{array}{l}\text { Pyrite + } \\
\text { pyrrhotite }\end{array}$ & $0,23-0,25$ & $0,43-0,52$ & $5-7$ \\
\hline
\end{tabular}

The information about presented in this table group of minerals - amphibole includes varieties:

1) monoclinic amphiboles: cummingtonite, actinolite, tremolite, grunerite;

2) alkaline amphiboles: riebeckite, glaucophane;

3) rhombic amphiboles: anthophyllite.

On the strength of the weakest intergranular contacts is iron-mica-magnetite quartzite, followed by alkali-magnetite quartzite, cummingtonite-magnetite quartzite and biotite-magnetite quartzite.

Sulphides in the ferruginous quartzites of complex composition are mainly pyrite. Dimensions of pyrite formations vary between 0.005 to $3-5 \mathrm{~mm}$. Forms of emphasis of pyrite are very diverse: from the rounded, equant, euhedral grains with well-educated faces (it is usually the smaller individuals from 0.005 to $0.1 \mathrm{~mm}$ ) to the needle, elongated curved, corrosive, skeletal, as well as patterns of substitution after magnetite, siderite silicates
It was found that ferruginous quartzite of complex composition of Lebedinsky deposits are rich in

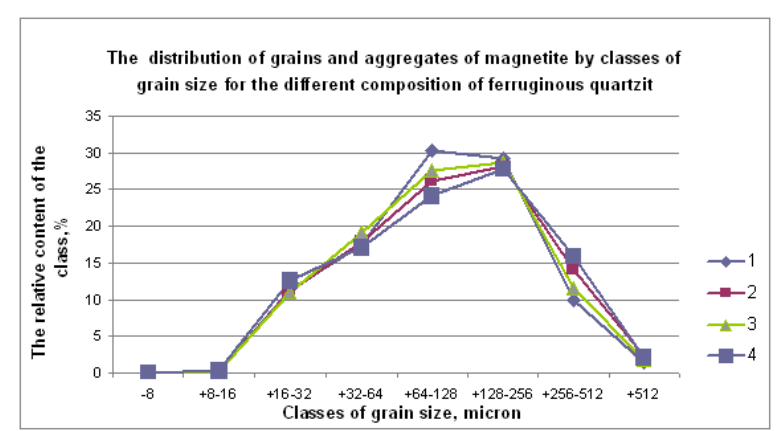

amphibole (35\%), mica (14\%), sulphides (up to $7 \%$ ).

Fig. 1 The distribution of grains and aggregates of magnetite by class size for the ferruginous quartzite of different composition (1 magnetite, 2 - magnetite with cummingtonite, 3 - magnetite with alkaline amphibole, 4 - cummingtonite-magnetite)

The study of grain size distribution of useful component in different ferruginous quartzite species showed a significant difference in the magnetite grain size in quartzites of complex composition. This is confirmed by the data presented in Figure 1.

The difference in the magnetite grain size in quartzites of complex composition results in significant changes of their physical and technical properties, and results in inefficiency in the traditional technological schemes of processing [3].

Analysis of the data showed that it is advisable to extract useful components using fractional magnetic separation followed by of coarse- and fine-grained enrichment by the individual schemes.

Further experimental study of the effectiveness of individual recycling processes and the choice of optimal conditions and modes was performed using multiscale modeling methods of disintegration processes, fractionation and concentration of mineral matter.

\section{Tailings of non-ferrous metals}

The studies of the composition and structure of mineral matter tailings of nonferrous metals in the man-made formation "Svyatogor" showed that there are useful components in their composition. The result of the composition of a representative sample of the mineral matter is presented in Table 2.

The study of representative samples made by using X-ray diffractometry showed that they contained: chalcopyrite $(1.67 \%)$, sphalerite $(1.2 \%)$, pyrite $(57.6 \%)$, quartz (25.8\%), feldspar (8\%) and mica (6\%).

It was found that chalcopyrite in classes minus 2.0 plus $0.63 \mathrm{~mm}$ is full of incorrect inclusions in pyrite or occupying his veins in intergranular space. In the class minus 0.63 plus $0.40 \mathrm{~mm}$ appear loose grains of chalcopyrite, which quantity is in the range of minus 0.074 plus $0.043 \mathrm{~mm}$ increased to $70 \%$, and in the class minus $0.043 \mathrm{~mm}$ increased to $80 \%$.

The sphalerite in classes $+0.40 \mathrm{~mm}$ is found only in intergrowths with pyrite and non-metallic inclusions 
in the rare forms or small abnormal secretions in the intergranular space of pyrite. In the class minus 0.40 plus $0.315 \mathrm{~mm}$ appear free sphalerite grains (14\%), the number of which is gradually increased, reaching 87\% (class minus 0.074 plus $0.043 \mathrm{~mm}$ ) and $91 \%$ (class minus $0.043 \mathrm{~mm}$ ).

\section{TABLE 2}

TABLE OF CONTENTS OF EXTRACTED ELEMENTS IN THE NON-FERROUS METAL ORE WASTES STOCKPILED IN THE TECHNOGENIC FORMATION

\begin{tabular}{|l|l|l|l|l|}
\hline \multirow{2}{*}{$\begin{array}{l}\text { Grain size } \\
\text { classes, mm }\end{array}$} & \multirow{2}{*}{$\begin{array}{l}\text { Output, } \\
\%\end{array}$} & \multicolumn{2}{|l}{ Content, \% } \\
\cline { 3 - 5 } & & copper & zinc & sulfur \\
\hline$+2,8$ & 0,07 & 0,52 & 1,38 & 27,79 \\
$-2,8+2,0$ & 0,53 & 0,79 & 2,61 & 32,40 \\
$-2,0+1,4$ & 0,61 & 0,81 & 0,31 & 28,29 \\
$-1,4+0,63$ & 4,83 & 0,66 & 0,54 & 22,09 \\
$-0,63+0,40$ & 6,91 & 0,61 & 1,29 & 22,36 \\
$-0,40+0,315$ & 6,46 & 0,55 & 0,93 & 20,74 \\
$-0,315+0,2$ & 16,90 & 0,62 & 0,65 & 23,44 \\
$-0,2+0,125$ & 23,73 & 0,49 & 0,55 & 28,70 \\
$-0,125+0,09$ & 0,89 & 0,54 & 0,76 & 36,05 \\
$-0,09+0,074$ & 14,24 & 0,52 & 0,68 & 32,66 \\
$-0,074+0,043$ & 13,84 & 0,49 & 0,68 & 33,14 \\
$-0,043$ & 7,99 & 0,60 & 0.78 & 40,32 \\
Total & 100,00 & 0,55 & 0,72 & 8,18 \\
\hline
\end{tabular}

\begin{tabular}{|l|l|l|l|l|}
\hline \multirow{2}{*}{$\begin{array}{l}\text { Grain size } \\
\text { classes, } \mathrm{mm}\end{array}$} & \multirow{2}{*}{$\begin{array}{l}\text { Output, } \\
\%\end{array}$} & \multicolumn{3}{|l|}{ Distribution, \% } \\
\cline { 3 - 5 } & & copper & zinc & sulfur \\
\hline$+2,8$ & 0,07 & 0,06 & 0,13 & 0,06 \\
$-2,8+2,0$ & 0,53 & 0,76 & 1,93 & 0,52 \\
$-2,0+1,4$ & 0,61 & 0,90 & 0,26 & 0,59 \\
$-1,4+0,63$ & 4,83 & 5,78 & 3,64 & 3,68 \\
$-0,63+0,40$ & 6,91 & 7,65 & 12,43 & 5,33 \\
$-0,40+0,315$ & 6,46 & 6,45 & 8,37 & 4,62 \\
$-0,315+0,2$ & 16,90 & 19,02 & 15,35 & 13,70 \\
$-0,2+0,125$ & 23,73 & 21,11 & 18,31 & 23,54 \\
$-0,125+0,09$ & 0,89 & 3,81 & 4,12 & 4,84 \\
$-0,09+0,074$ & 14,24 & 13,44 & 13,49 & 16,07 \\
$-0,074+0,043$ & 13,84 & 12,31 & 13,29 & 5,86 \\
$-0,043$ & 7,99 & 8,71 & 8,69 & 11,12 \\
Total & 100,00 & 100,00 & 100,00 & 100,00 \\
\hline
\end{tabular}

The pyrite during grinding released from intergrowths significantly faster: if in a class minus 2.0 plus $1.4 \mathrm{~mm}$ it is found only $8 \%$ free grains of it, then in the class minus $0.074 \mathrm{~mm}$ plus $0.043-97 \%$, and in the class minus $0.043 \mathrm{~mm}$ pyrite almost disclosed. It often grows together with chalcopyrite $(2-11 \%)$, rarely sphalerite (1-6\%) and non-metallic (3$8 \%)$.

These results indicate that the waste of non-ferrous metal ores keeping for a long time in man-made tailings are rather difficult target of enrichment, as valuable minerals in them closely grow together with pyrite. Thus sphalerite released from pyrite intergrowths much better than chalcopyrite (respectively $91 \%$ and $80 \%$ in the class minus 0.043 $\mathrm{mm})$. To extract chalcopyrite and sphalerite very fine grinding of the sample is necessary, which leads to overgrinding of pyrite and formation of sludge, complicating the selective separation of minerals [4].

The difference of the structure and composition of the mineral substances extracted from man-made formation and incoming to the enrichment is illustrated by the graphs shown in Figures 2 and 3 .

It was found that when the grinding time is $20 \mathrm{~min}$ the content of the class minus $0.074 \mathrm{~mm}$ from the waste ore is a $35 \%$ increase than in the ore crushed material.

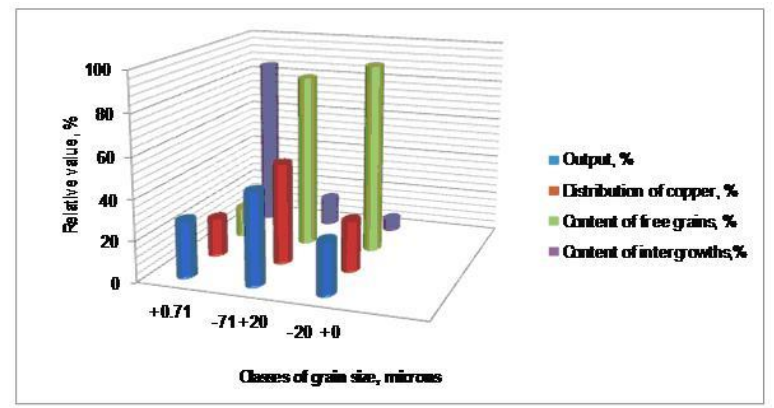

Fig. 2. The characteristics of different grain size classes of disintegrated ore coming onto the enrichment

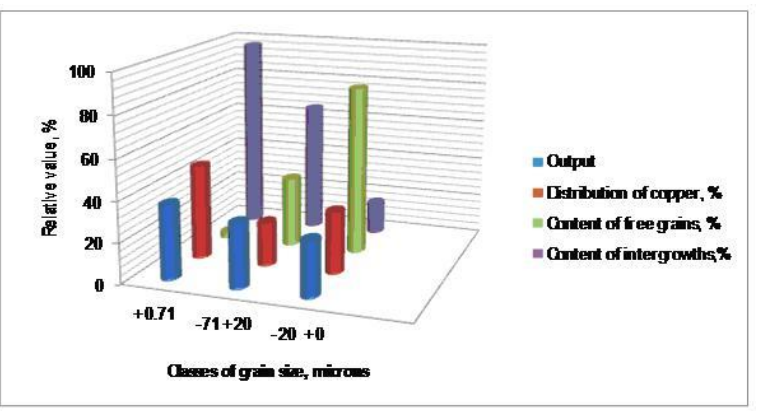

Fig. 3. Characteristics of the different grain size classes of mineral matter in nonferrous metals technogenic tailings

In Figures 2 and 3 it the results of particle size, mineralogical and chemical analysis of disintegrated mass and waste of ore Volkovsky deposits on JSC "Svyatogor" are shown.

These results revealed a significant difference in the distribution of the useful components in mineral matter. Studies have shown that most of the copper minerals in the raw material (55\%) (Figure 2) is in a class of $-71+20$ microns, with $86 \%$ in the form of free grains, in class +71 micron copper minerals are represented by intergrowth $(85 \%)$ in the class -20 microns dominate free grains $(95 \%)$. In the tailings (Figure 3) the character of the distribution of copper minerals is different: most of the copper accounts for class +71 microns $(47.26 \%)$, and in the class $-71+20$ micron there is a minimum distribution of copper $21.8 \%$.

Comparing the data presented in Figures 2 and 3, it can be noted that the major losses occur in aggregates of copper minerals in a class of 71 microns, and to a 
large extent on the availability of grain in classes $71+20$ and $-20+0$ microns.

The study found that non-ferrous minerals of stale tailings represent the transformed mineral association with specific surface and technological properties different from the ore mineral associations.

The investigations have shown that the processing characteristics of stale ore wastes and disintegrating ores vary due to the changes in the surface properties of their constituent minerals. Experiments have shown that the changes in the technological properties of mineral matter are associated with the manifestation of the following factors:

- an increase in technogenic material of fine fractions;

- the presence of oxidized forms of copper minerals, which are suppliers of copper cations in the liquid phase;

- oxidation of the surface of the non-ferrous metal sulphides;

- preservation of pyrite flotation activity.

Further experimental studies of disintegration processes, fractionation and separation of mineral matter of ferruginous quartzite of complex composition and waste of non-ferrous metal ores made using multiscale modelling allowed us to establish patterns of changing the efficiency of these processes, depending on the conditions and characteristics of their implementation.

On the basis of the pilot study the selection of the optimal parameters of the individual processes to ensure efficienty of mineral substances processing is carried out.

\section{RESULTS AND DISCUSSION}

\section{Recycling of ferruginous quartzite of complex composition}

The research of process of complex composition ferruginous quartzite recycling was carried out with specifics of existing manufacturing base for processing of their conditioned varieties.

The analysis of data on the distribution of magnetite in the products of disintegration has shown that for a quality magnetite concentrate of ferruginous quartzite of complex composition it is advisable to use a scheme realizing the fractional magnetic separation with split-flow disintegrated masses by size. In this case the disintegration of multimineral aggregates should be carried out in three stages (see Figure 4).

The experiments showed that the disintegration of the ferruginous quartzite with the use of autogenous grinding mills the performance of the operation depends on the mass fraction of grinding media and of milled classes in nutrition, as well as the water consumption. It was found that the maximum performance is achieved when the ratio between the grinding and milling classes is $2.3-2.6$.

It was found that as the number of stages of wet magnetic separation increases the metal extraction into concentrate, and the number recleanings for ores of complex composition, should be: three - "basic" and two - "roughing" [5].

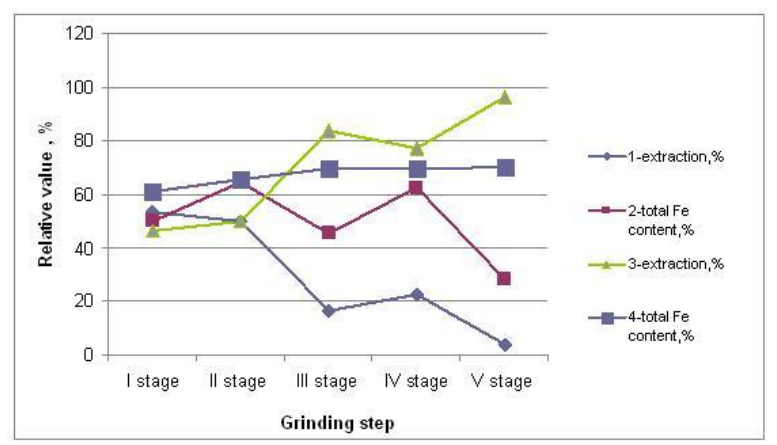

Fig. 4. The influence of the grinding step to retrieve the value (in\%) and the concentration of $\mathrm{Fe}$ total. (in\%) in the products of disintegration of the ferruginous quartzite of complex composition with grain size $+0.045 \mathrm{~mm}$ (lines 1,2) and $-0,045 \mathrm{~mm}$ (lines 3, 4)

Experiments have shown that the use of the processing of ferruginous quartzite thin fractionation of complex composition that uses high-frequency vibration exposure, reduces the amount of material to be sent to the secondary disintegration, and ensures growth of mass fraction of iron in the concentrate, as well as smaller overgrinding of iron minerals than using hydrocyclones. The study of the influence of various schemes disintegration of the ferruginous quartzite of complex structure on the efficiency of the process, different by ratio of the number of primary and secondary crushing mills, showed that the obtained magnetite concentrates are similar in mass fraction of iron $(65,98-66,22 \%)$, however, waste of concentrating cycles for different disintegration schemes differ significantly. Their output ranged from 10.02 to $11.04 \%$ when the mass concentration of total iron content varies from 8.99 (Figure 3-2) to $11.45 \%$ (1:1) and magnetic iron content varies from 0.77 to $1.65 \%$ respectively.

Conducted research of polymineral masses fractionation process showed that the increase of solid mass fraction in griddle nutrition from $30 \%$ to $40 \%$ reduces the effectiveness of sifting for $8 \%$, the increase up to $50 \%$ - for $10 \%$, and increase the frequency of griddle vibration from 42 to $50 \mathrm{~Hz}$ reduces the efficiency of sifting by $4 \%$ when the mass concentration of solid in griddle nutrition is $30 \%$; when the mass concentration of solid in grate nutrition is $40 \%$ the effect of vibration frequency on the effectiveness of sifting is insignificant.

Recommended scheme of treatment of complex composition ferruginous quartzite stipulates ragging in boulder crusher KKD 1500/180. Crushed to a particle size $0-350 \mathrm{~mm}$ product is transported by conveyors into the enrichment house, where conveyor system distributed it over bins.

At the processing plant crushing and enrichment of ferrous quartzites is carried out on the scheme of three-way grinding with five stages of magnetic separation (ratio of volume of mills in stages is $3: 2$ ). 
Experiments have shown that the scheme $3: 2$ is a basic scheme that will ensure the raw magnetite concentrate of ferrous quartzites complex composition, providing the production of concentrate with Fe content 66,6-68,7\%.

Crushed ore is fed to the horizontal conveyor, where reloaded onto conveyors filing the ore to the primary mills.

The first stage of grinding is carried out in three wet grinding mills operating in a closed cycle with spiral classifiers. The first stage provides grinding to a particle size of $65-75 \%$ of the class - $0,071 \mathrm{~mm}$. The drain of spiral classifier enters the first stage separation. Each block of separators contains a sequentially installed three drums, i.e. separation is carried out in three stages. Tails of the first stage of magnetic separation are sent to the tail tray. The first stage middlings of magnetic separation enters the dibhole from which is fed to the classification at the griddle of fine screening. Oversize material of fine screening comes to the secondary grinding. Discharge of the mill supplied to the second stage of wet magnetic separation. Wastes of the second stage of wet magnetic separation are sent to the tail tray, and middlings return to thin fractionation.

Undersize material of fine screening fed to an additional classification in hydrocyclones. Hydrocyclone separation occurs on a class $-0.071 \mathrm{~mm}$. Discharge of the hydrocyclones, containing $85 \%$ of the class $-0.045 \mathrm{~mm}$, fed to the third stage of wet magnetic separation in two steps. Tails of the third stage of magnetic separation are sent to the tail tray. Magnetic product after the third stage of magnetic separation is the final product, corresponding to the requirements for ordinary magnetite concentrate.

A high-quality magnetite concentrate is carried out on an additional scheme in which produced magnetite concentrate fed into the radial thickening, where they compacts up to the solid mass fraction of $60 \%$. Underflow solids are pumped to the average in the stirrer.

After compaction and stirring ordinary average magnetite concentrate fed to the grinding to a particle size minus $0.045 \mathrm{~mm}$ of $98 \%$. Discharge of the mill is supplied to the first stage of wet magnetic separation. The obtained concentrate is fed to the classification at the thin fractionation griddles, and tails are sent to the tail tray. Oversize material of fine fractionation returned to the mill, and the underflow material is fed to the slime removal, which discharge with solid mass fraction of $0.12 \%$ goes to the recycling of water and sand is applied fed to the second stage of magnetic separation. The obtained product - high quality magnetite concentrate with $\mathrm{Fe}$ content of $70.0 \%$ is the final product.

Conducted research trials showed the promising use for the operation of magneto-gravitational condensation of the concentrator (MGS-0,5). It was found that the mass fraction of solids in the initial nutrition of magneto-gravity concentrator does not affect mass fraction of $\mathrm{SiO}_{2}$ in the concentrate, and the mass fraction of solid in concentrate affects slightly.

It was found that the mass concentration of $\mathrm{Fe}_{\text {total }}$ $68.56 \%$ in the nutrition while using magnetic-gravity concentration the concentrate with $\mathrm{Fe}_{\text {total }} 69.69 \%$ and $\mathrm{SiO} 23,36 \%$ is obtained. The experiments also showed that the reduced magnetic field strength of MGconcentrator allows to produce concentrate with a smaller mass fraction of $\mathrm{SiO}_{2}$.

Recycling of non-ferrous metals enrichment

Implementation of a complex research processes of non-ferrous metal ores waste processing, in which the flotation separation techniques of polimineral systems used, allowed to choose an optimal combination and modes of specific operations execution.

Investigations have shown that pyrite, which is the main ore-forming mineral of pyrite deposits (up to $90 \%$ of the sulfide) has a significant effect on the oxidation of sulphides of nonferrous metals and on precious metal mineral associations. Processes of oxidation of sulphides are intensified by mikro galvanic couple (nonferrous metal sulphides with pyrite, which play the cathode role).

It is stablished that in the processing of the mineral matter it is expedient to use the combined technological schemes and additional fractionation with a conclusion in the final products of fractions that have similar technological properties. This allows to recycle them using individual technologies, which improves the technological parameters and the complexity of the use of raw materials [6]. Occurring in the technogenic formation hypergenic processes cause a high acidity which was produced at the contact of heterogeneous system with water.

The study of the effect of old tailings grinding time on the $\mathrm{pH}$ shows that with increasing the duration of grinding and thus reducing the size of the solid phase, the acidity of the environment is stabilized (Figure 5).

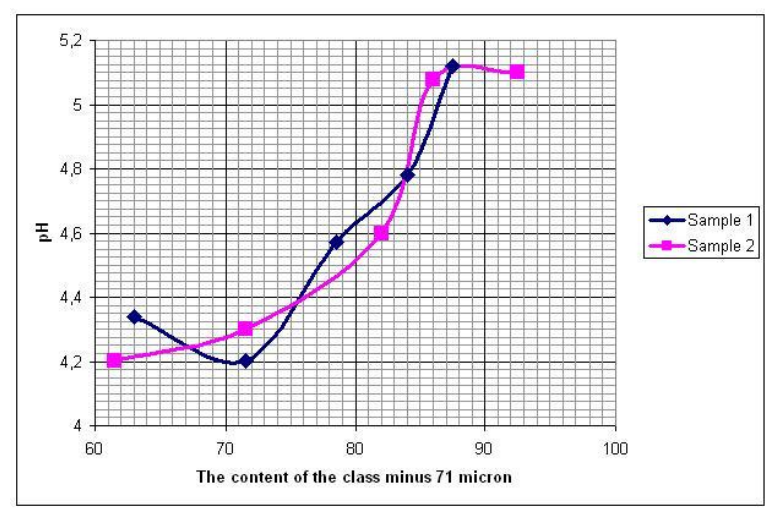

Fig. 5.Change in $\mathrm{pH}$ with a decrease in size of the solid phase during the grinding process to investigated old tailings tests

The study of the kinetics of the oxidation rate of ore minerals change during grinding in the liquid phase of different compositions allowed to select rational methods of purposeful changing their ability to flotation recovery. 
Figure 6 shows the dependence of the oxidation rate of unit mineral surface by oxygen during grinding in a saturated solution of lime to time. The curves of sulfide oxidation rate of unit mineral surface by oxygen unit surface show that the highest rate of sulphides oxidation in the prescribed range observed in the first minutes of grinding, and then with increasing grinding time is tapering off.

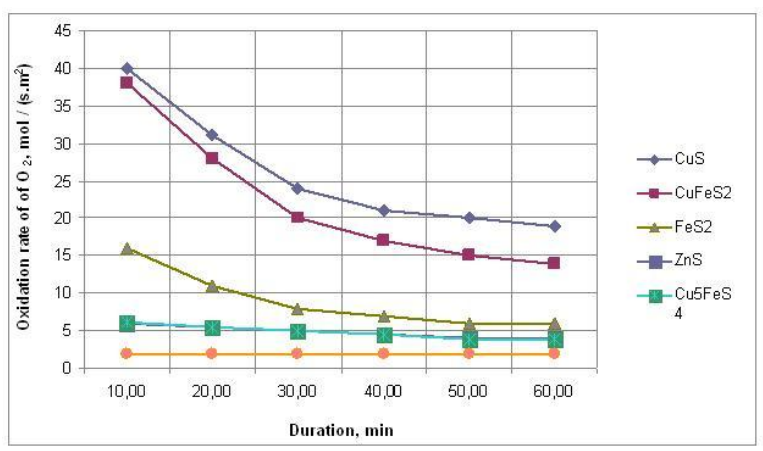

Fig. 6. rate of absorption of oxygen by a unit surface sulphides during grinding in a saturated solution of lime in time

Decrease with time of the rate of oxidation per unit area of sulphide minerals in the grinding process is mainly due to the fact that the oxidation of sulfides in highly alkaline medium occurs with the consumption of alkali, and with a decrease of alkalinity the rate of oxidation of sulfide minerals decreases. Other, less significant cause of it, and the fact that oxidation of the oxygen concentration in the solution is reduced as long as the rate of dissolution of oxygen in the slurry reaches the speed of oxidation.

The experiments showed that the highest rate of oxidation chalcopyrite has, leading to significant changes in surface properties, complicating its flotation recovery. When the natural duration of redox processes in the tailings, along with the activation of the surface of sphalerite by copper cations, sphalerite oxidation occurs with the formation of oxidized forms of zinc minerals - smithsonite, zincite and calamine, which are practically not extracted with flotation methods of enrichment. Pyrite, which in redox processes acts as the cathode, the most remains flotation activity.

It was found that fine regrinding of large fraction of old waste of ores for subsequent gravitational and flotation extraction of useful components is a necessary operation, allowing for the inter-cycle operation of gravity or flotation of copper extraction.

Investigations have shown that the use of aeration in the collective and selective flotation, can improve performance of the process. Moreover, the best results are obtained with continuous aeration during 5-10 minutes. At the same time the extraction of copper in obtained after gravity separation concentrate increased by $20 \%$, in the collective copper concentrate by 20 $25 \%$, zinc more than 2 times, greatly improving the quality of concentrates, and the extraction of zinc in rough zinc concentrate at any lime consumption by 10
$20 \%$ higher than without aeration when mixed with reagents.

It was also found that with increasing temperature up to $60^{\circ} \mathrm{C}$, the efficiency of the separation process in the zinc flotation of pyrite and sphalerite with different duration of mixing zinc recovery increased average by $10 \%$, followed by a further increase in temperature decreases. Extraction of iron in the rough zinc concentrate with increasing temperature up to 95 ${ }^{\circ} \mathrm{C}$ decreases by 2 times. The optimum temperature is in the range $40-65^{\circ} \mathrm{C}$, and the duration of the mixing has a significant effect of up to $20^{\circ} \mathrm{C}$. Oxidationthermal effect on the sulfide polymineral mixture increases the difference in the oxidation of sulphide minerals surface and the various changes in their flotation properties. As reagents accelerating the oxidation of sulfides by heating, used lime, calcium hypochlorite, hydrogen peroxide.

Investigations have shown that the technology of recycling of non-ferrous metal ores should include operations - disintegration; washing; classification; desliming on class minus $0.010 \mathrm{~mm}$; gravitational extraction of useful components, regrinding of sand fraction; selective flotation to produce copper and pyrite products, copper zinc middlings and tailings; selective flotation of copper-zinc product.

\section{CONCLUSION}

The executed researches have shown that the processing of mineral substances of complex composition ferruginous quartzites and previously stockpiled wastes of non-ferrous metals produces quality conditioned metal concentrates. The use of specially selected for each object of the study complexes of technological operations carried out in specific conditions and modes, provides reception the concentrate of complex composition ferruginous quartzites with $\mathrm{Fe}$ content of at least 68 , and $5 \%$ from the previously stockpiled tailings base metal ores concentrates with no less $16 \%$ of copper and at least $48 \%$ of zinc. Use of the proposed technology solutions will reduce the amount of that will be hosted on the surface of environmentally hazardous mineral matter, and is able to improve the environmental situation in the regions.

\section{$\mathrm{V}$ ACKNOWLEDGMENTS}

This work was supported by the Ministry of Education and Science of Russia. Contract № 16.515.11.5037.

\section{REFERENCES}

[1] Velesevich I.V., Vinnikov V.A., Zilbershmidt M.G., Tereshchenko E.I. Structure and structural conditions of ferruginous quartzites of complex composition. Mining informational and analytical bulletin, № 11, 2011.

[2] M. Zilberchmidt , M. Shpirt, Rehabilitation of coal waste dumps. Field pilot application, Advances in Mineral Resources Management and Environmental Geotechnology, Hania 2004, Greece, 455-460. 


\section{COMPOSITION}

[3] Vinnikov V.A. Gzogyan T.N. Fractionation and separation schemes of ferruginous quartzite of complex composition Mining informational and analytical bulletin, № 8, 2012.

[4] Bocharov V.A., Ignatkina V.A., Chanturia E.L. Problems of complex reprocessing of pyrite flotation copper-zinc ore tailings. "Non-ferrous metals», № 12, 2011.
[5] Vinnikov V.A., Gzogyan T.N. Intensification of separation processes in enrichment schemes of ferruginous quartzite of complex composition. Mining informational and analytical bulletin, № 9, 2012.

[6] Bocharov V.A., Ignatkina V.A. Mineral processing technology. V.1 and V.2. Moscow, Ore and Metals, 2007. 